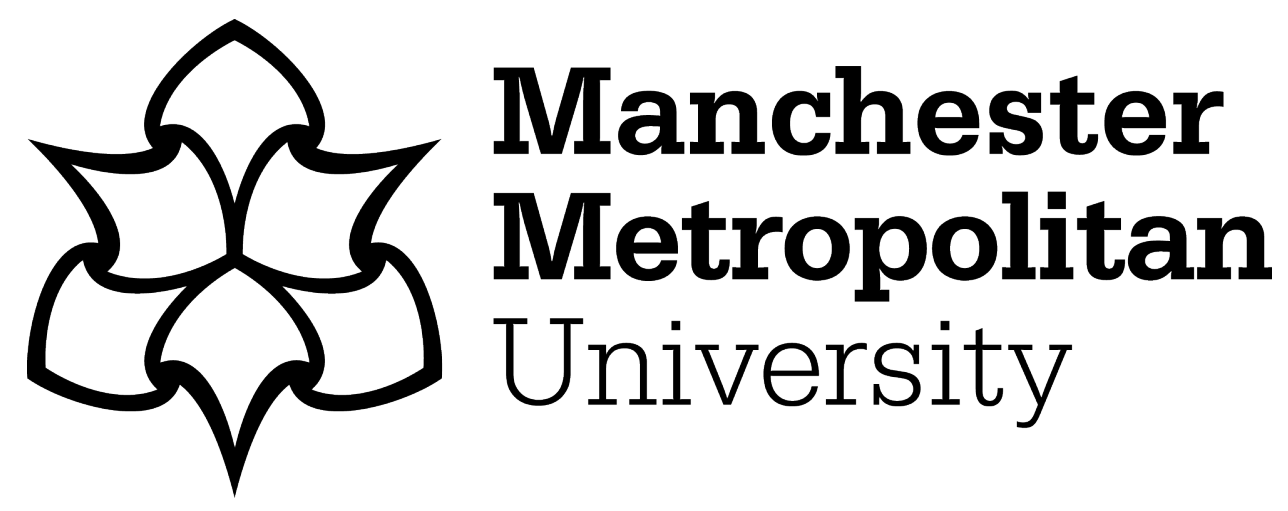

Sikes, Pat and Hall, Mel ORCID logoORCID: https://orcid.org/0000-00025657-0278 (2020) Too close for comfort?: ethical considerations around safeguarding the emotional and mental wellbeing of researchers using auto/biographical approaches to investigate 'sensitive' topics. International Journal of Research \& Method in Education, 43 (2). pp. 163-172. ISSN 1743-727X

Downloaded from: https://e-space.mmu.ac.uk/623918/

Version: Accepted Version

Publisher: Informa UK Limited

DOI: https://doi.org/10.1080/1743727x.2019.1636025

Please cite the published version 


\title{
Too close for comfort?: ethical considerations around safeguarding the emotional and mental wellbeing of researchers using auto/biographical approaches to investigate 'sensitive' topics
}

\section{Keywords}

Sensitive research / relational ethics / ethics of care / auto/biographical approaches / researcher well-being / dementia

Words 6624

\begin{abstract}
Auto/biographical narrative research that touches on 'sensitive' areas can elicit accounts that researchers may find distressing and threatening to their emotional and psychological health. In this paper we offer a 'confessional tale' through which we consider our experiences of investigating a sensitive and painful topic from the perspectives of the Principal Investigator who was intimately acquainted with the field of study because it affected her own family, and of the Research Associate who had no prior experience of the substantive area. We discuss how we dealt with our distress and pain and offer some novel suggestions that other educational researchers using qualitative approaches might adopt to help ensure that their research is ethical in that the wellbeing of researchers, as well as participants, is safeguarded.
\end{abstract}

Auto/biographical approaches of various kinds are increasingly popular in educational research, whether they are employed to investigate the perceptions and experiences of particular groups of students or educators, or to interrogate education related aspects of a researcher's own life. Research involving auto/biographical narratives clearly 
requires careful ethical consideration in order to protect the individuals involved and there is a substantial literature around the various issues that can be implicated in work of this kind (Goodson, Antikainen, Sikes and Andrews 2017; Iphofen and Tolich 2018; Turner et al 2018). When the research touches on 'sensitive' areas (Lee 1993; Renzetti and Lee 1993) the need to be alert to potential damage to participants is obviously even greater. It is important to be aware however, that researchers, and particularly those using qualitative approaches especially perhaps auto/biographical approaches and research methods influenced by feminist traditions (Sampson, Bloor and Fincham 2008) can also be at risk of harm and on a number of fronts. That this is the case has been well recognized by those working in the fields of health-related, anthropological, psychological and sociological studies (Behar 1996; Bloor, Fincham and Sampson 2007; Dickson-Swift et al 2007, 2008, 2009; emerald and Carpenter 2015). It would seem though, that educational researchers have paid less attention to, and may consequently be under-prepared for, the issues that can arise. To be truly ethical all dimensions of the wellbeing of the educational researcher need to be safeguarded.

Here our concern is not with the sorts of physical dangers that researchers may be at risk of if, for example, working in war zones or coming into contact with criminal activities. It is not with the potentially negative reputational and career consequences of investigating certain topics, and using particular methodologies, methods and styles of writing and representation - especially, perhaps, those that involve personal disclosure (Brooks et al 2014; Sikes 2006). Our interest is, rather, in the emotional and psychological discomfort and more significant harm that can be experienced by educational researchers employing auto/biographical approaches to investigate 
sensitive issues; and in illustrating and discussing how a relational ethics of care (Ellis 2007; Noddings 1984) with regard to participants and to each other as fellow researchers, was helpful to us and may be of use to others.

Emotional and psychological harm can arise as a result of eliciting and hearing participants' distressing stories, leading to what has been called 'vicarious traumatization' (Pennebaker 1990, 118). This traumatization can be exacerbated when the researcher is investigating a topic touching on personal, experiential, insider knowledge (Sikes and Potts 2008). In these cases research can begin to feel too close for comfort (Chatham-Carpenter 2018; Harris 2015; Liddiard 2013). This was our experience and so in this paper we share a 'confessional tale' (Van Maanen 1988) and consider some of the personal emotional and psychological costs of investigating a sensitive and painful topic from the perspective of the principal investigator - Pat who devised the study and who was intimately acquainted with the substantive field, and from the point of view of the research associate - Mel - who was appointed to the project having no prior experience of dementia. First we outline the study in question, then Mel describes the way in which a significant event in her own life resonated with her work on the project, followed by Pat reflecting on what it was like to be living through similar experiences to those being investigated. Finally, we offer some thoughts on how we sought to deal with potential and actual emotional and psychological distress.

\section{The study}


The study had auto/biographical origins in Pat's observations of how her husband's young onset dementia -YOD - negatively affected her children who were 13 and 15 when their father first exhibited behaviours later attributed to the condition. Most areas of their lives, including their educational careers, were impacted by his illness and continue to be since at the time of writing they are 27 and 29 and he is still alive, albeit receiving end of life care.

As a sociologist convinced by C. Wright Mills' call to sociologists to use the sociological imagination ethically and critically and in such a way that the personal uneasiness of individuals is focused upon explicit troubles and the indifference of publics is transformed into involvement with public issues' $(1970,11-12)$, Pat felt an ethical compulsion to exploit her position as an academic to investigate how it was for others in a similar position to her children (Sikes 2015). She received funding from the Alzheimer's Society for a study - The perceptions and experiences of children and young people who have a parent with dementia - which, uniquely within dementia research, took an unstructured narrative auto/biographical approach with a view to yielding accounts to inform policy and practice.

With rare exceptions, the majority of the few studies there have been within the field have not directly asked children and young person with a parent with YOD what it is like for them. This has meant that individuals' stories are not being heard thereby preventing private troubles from being recognized and made public concerns (Mills 1970, 11 - 12). Whilst acknowledging the problems around claims to 'give voice' articulated by such authors as Jackson and Mazzei (2009) and Gullion (2018) the decision to use narrative auto/biography was based on a commitment to recording and 
using what the young people said to 'force a confrontation with other people's subjective perceptions' (Goodson and Sikes 2001: 7). Put simply, the situation seems to be that unless you are a young person experiencing parental dementia or their 'well' parent or a closely involved family member, no-one else, including professionals, is likely to have a realistic idea of what it means for your life on a daily and on a long-term basis. Appropriate support requires such information, especially, it is suggested, because the predominantly quantitative evidence that is available indicates that these young people are likely to experience a greater degree of social, emotional and psychological upset, physical and mental ill health, financial hardship and family break up than do children who are adults when their parents get dementia: they are, therefore likely to be in need of help which currently rarely exists (see for example Allen, Oyebode and Allen 2009; Aslett et al 2017; Gelman and Rhames 2016; Hutchinson, Roberts, Kurrle and Daly 2014).

Our study involved 24 participants aged 6 to 31, with the majority between 16 and 24, who had, or had had, a parent with a form of YOD, that is, dementia diagnosed before the age of 65 . Most of the participants' parents had been diagnosed in their early 50 s.

Over a period of 18 months the young people were simply invited to tell their stories of parental dementia, with the four under 10s participating in 'my day', family tree, drawing and play activities (James 2005). No specific questions were asked in order to try to minimize influence. Nor were such questions needed because the opportunity to speak freely was taken up enthusiastically with sessions lasting between 45 minutes and two hours plus. Most participants were seen two or three times which in some cases has led to them and Mel forming a continuing relationship - not friendship as 
method (Tillmann-Healey 2003) exactly, but definitely introducing a significant compassionate and relational (Ellis 2017) element to the investigation. The longitudinal element also helped provide a sense of how the progressive nature of dementia is experienced and perceived: notably 4 parents died during the course of the project. The study received ethical clearance from our university but obviously ethical concerns were a constant preoccupation with on-going consent being sought and obtained throughout each interaction commensurate with the relational ethics of care approach built in to the research design.

The narratives participants shared unequivocally suggest that parental YOD is extremely distressing and in some cases, life changing. Elsewhere we have written about: the period leading up to diagnosis, experiencing parental change, grief, how dementia can affect family relationships, and the impact of parental dementia upon educational careers (Hall and Sikes 2016a, 2016b, 2016c, 2017; Sikes and Hall 2016, $2017,2018)$. Now we move on to offer some reflections on how our involvement in this study affected us as researchers and in our lives more generally.

\section{Hearing difficult stories from Mel's perspective}

In my interview for the post Pat emphasized the emotionally difficult nature of the research and I, of course, was, in theory, mindful that this was a sensitive area requiring a tactful approach. I looked forward to being involved in a study that I believed was important and had transformative potential. I thought, and now know that, the costs would outweigh the benefits, although at the start, largely because the limited literature had not provided detailed first person accounts telling of how painful parental dementia could be, neither Pat nor I appreciated how distressing some 
of the participants' stories would be. Nor did we know how our personal biographies and idiosyncratic circumstances would combine to affect how we experienced the study.

Having had no previous personal contact with someone with dementia I was well aware that there was much that I did not know. However I was on a steep and distressing learning curve because I undertook all of the interviewing totaling something in the region of 68 hours of talk. I also did all of the transcription and, as Nikki Kiyimba and Michelle O'Reilly (2016) note, 'the process of transcription by its nature involves the repeated listening of data to capture the words spoken and this repeated listening of disturbing material can have a lasting impact' (469) (see also Dickinson-Swift et al 2007, 336 - 337). I recall feeling particularly distressed following interviews where: Taylor ${ }^{1}$ disclosed a suicide attempt, connected to the emotional impact of their parent's illness; and 20 year old Juliet talked about having to have funeral arrangements in place for when her mum died.

I had tried to create a safe, comfortable, non-judgemental setting where people felt able to talk freely. It certainly seemed that I succeeded because in talking about how it was for them participants voiced experiences - shared 'dangerous knowledge' (Pietikainen 2004; Turner 2016) - that challenged what, in the UK, have come to be dominant master narratives about dementia such as denying that their mum or dad was 'still the same' as they were before they developed YOD or saying that their parent and their family were not 'living well with dementia' (Hall and Sikes 2017). These dominant narratives, like others similarly constructed to prompt more positive attitudes and behaviours towards marginalized groups, play an important role in 
raising awareness and changing attitudes therefore, questioning them can have social censure consequences for participants and raise ethical implications for researchers (Hall and Sikes 2017; Sikes and Piper 2010). Our view was that, even though some accounts did challenge dominant narratives - usually offering a justification for why they did so - it would be wrong not to include them (suitably anonymised) in publications or oral presentations because they reflected what participants said their experiences and perceptions were. Lather (2009) argues that re-presenting narratives of pain can be a form of appropriation constituting violence against participants but we had been given consent by the young people, and were even exhorted, to use them. We believed that the stories in all their rawness needed to be heard if they were to have any chance of influencing policy and practice. Nonetheless such narratives were difficult to hear, both for the painful personal content they reported and with regard to the wider impact they might have when others heard them and, lacking experience, might be critical.

The longitudinal nature of data collection meant being in ongoing contact with research participants which, as Ellis notes, can morph into friendship (2007). As the study progressed and I gained a better sense of the nature of dementia whilst also beginning to establish caring relationships with the young people, I came to understand, in an experiential and embodied, rather than theoretical sense, that some would likely lose their parent during the course of the research. When emailing to arrange follow-up interviews I knew that the response might report a death and wondered how I would be able to deal with that. Death and loss continue to be taboo subjects and I worried about showing any awkwardness. I thought I had the necessary research skills to be appropriately empathetic but, in truth, I was frightened of death. 
There were times when I found myself in tears travelling home from interviews, feeling exhausted by conversations which frequently were concerned with grief and anticipated parental death which, to be honest, is one of my own worst nightmares. On this topic especially, participants' stories were projections of my own (TillmannHealy and Kiesinger 2001, 100), making their impact on me all the more salient. Thus although I was used to working on the train on the way home, sometimes it was necessary to say to Pat 'I'm going to be reading nothing more taxing than a magazine' for the rest of the day. I needed to distance.

Although I was in my 30s, I had no intimate experience of death and consequent grief Just two months into data collection however, I was to receive a crash course when I had and was devastated by, a miscarriage. Although dementia and miscarriage grief are different experiences, what happened to me set the tone for my way of connecting with individuals dealing with pain and loss. I now knew, first hand: what it was to be able to silence a room with grief through the stigma it carries; how grief can shatter assumptions about the world; the everyday toll grief takes; how awkward some people can be around others' loss; and, how I appreciated empathetic encounters. Thus my unborn baby proved to be a precious resource that enabled me to offer suggestions, when appropriate, about what had helped me cope with my grief. Perhaps most significantly, I heard about project investigating miscarriage for which I volunteered and being on the other side of a study gave me an appreciation for 'our' young people's willingness to be involved and a sense of how important it was for me/them to tell my/their stories and be heard. 
The miscarriage also served to deepen the relationship between Pat and I and highlighted the relational ethical approach we had adopted. When I first knew I was pregnant, only 4 months after I began work on what was a 2 year contract, I didn't say anything. When it began to look like I was losing the baby, I told Pat and her response immediately made me feel looked after in a very real way, both emotionally and practically, From the start Pat had made it clear that her family's dementia experience was the catalyst for the study. I knew, from her words and her various writings, that she valued and respected emotions and caring ethical relationships and their place in the research process in terms of working with participants and between researchers, making me feel safe to be vulnerable. I was also aware of her vulnerability and, because of how she had been with me, was able to reciprocate in caring for her in her vulnerability. I was conscious that participants' experiences were similar to those of Pat's children - which could have made transcripts painful to read. I felt protective of her. As was the case for Lisa Tillmann Healey and Christine Kiesinger (2001), and over the course of the study, our approach was increasingly grounded in an ethics of care whereby we felt "emotionally and morally compelled to "do it right" and do right by each other' $(2001,104)$ - and by the participants of course.

\section{Pat's thoughts on living through similar experiences to those being investigated}

This was auto/biographical research in that it arose out of my personal experience, focused on participants' lives, and would inevitably be interpreted through frames, beliefs and values that were rooted in mine and Mel's biographies. Autoethnography (Ellis and Bochner 2005) was not, however, part of the formal research design in that I was not intending to reflect on and write in project outputs about my own experiences of living with my husband's dementia in the way that Carolyn Ellis 
(2018) wrote about her partner's life and death with emphysema. Nor was I doing this research in order to better understand those experiences for personal and therapeutic reasons: my focus was on the perceptions and experiences of children and young people with a parent with YOD with a view to informing policy and practice so that their needs for support might be better met.

On the basis of what happened in my family I expected to hear distressing stories although as previously noted, the limited literature had not prepared me for how disturbing some would be - and this was borne out when Mel passed on the transcript of her first interview. This was with a 24 year old man who told how he and his family had lived through a bewildering time as, over four years, whilst he was at school and university, his father's behaviour became out of character and increasingly bizarre. I knew about what this was like: as Liz Stanley puts it I was 'knowing because experiencing' (1993, 205). Thus I was familiar with: the strange and expensive purchases; the increasing lack of interest the father showed in his children's lives and how that hurt them; the familial attempts to construct stories, pre-diagnosis, which gave explanations other than dementia for what was going on; the bursts of anger; the confusion; the fear about what might happen next. My family had moved beyond this stage some years ago but this transcript took me right back in a surprisingly visceral fashion. I could remember and feel the feelings described with a shocking immediacy. And so it was with each subsequent transcript. Of course, no two people with YOD are the same but the confusion, grief, accommodations, decisions, consequences and feelings expressed by the participants resonated with my perceptions of what my kids - and myself - had gone, and were going, through. Every reading was upsetting. 
Years ago, as a new mother, I had researched the impact of parenthood on educators prompted by how I had come to see my children in the children and university students I encountered in my work (Sikes 1997). The stories of the parents participating in that study, in which I had done all of the interviewing and transcribing, had touched me more deeply than had auto/biographical narratives I'd collected in the course of other projects with which I was less personally connected. This YOD work, however, was something else entirely in terms of its emotional impact upon me.

Mel and I kept in close touch as she travelled around the country to see participants, letting me know when she'd arrived and when she left and filling me in on how the interview had gone. This contact was partly to do with ensuring that she was safe but also because I wanted to be as involved as possible. What she told me always evoked strong emotions, due to recognition and/or because of empathy and/or apprehension of what my family might next encounter. I had not expected these feelings to be so immediate, strong and painful, nor that I would find it so difficult to get them out of my head.

When I received the transcripts I read through them and often ended up in tears usually because I personally identified with what people said. For example, comments I wrote on the documents included:

This has made me cry..... Her words about applying for POA [power of attorney] took me right back - total nightmare and for a kid to have to be doing this .... 
I was really struck by the similarities with [my son's] relationship with his father

I was interested in what she said about her mum not recognizing the significance of presents. I have experienced this. [My husband] no longer enjoys presents - and that removes a way of relating....

At times it seemed like my world was constructed around dementia: I was reading the transcripts and dementia related academic articles in my professional life and my personal life was shaped by negotiating and living with my husband's dementia. It felt that there was little let up.

When the project began my husband was looked after by a carer who came into our house whilst I was at work. As his condition changed we - our children, the carer, staff from the local YOD service - came to feel that we could no longer meet his needs or keep him safe at home. Moving him into residential care, around six months into the project, is probably one of the hardest things I have ever done.

In my reading around dementia I had come across many articles touching on spousal carer stress and was, theoretically, aware of the dis/stress experienced when a partner moved to a care home. For me now that dis/stress became embodied. I experienced profound grief and guilt to the extent I could no longer function effectively and was signed off from work for three weeks. I spent much of this time unable to do very much but lie in bed and cry about me, my husband's plight, and about the situations the participants had described. Some weeks after I had returned to work and begun to cope a bit better, Mel told me that the mother of one of our participants whom she'd 
visited just before I went on leave had also had to place her husband in care and was having a similar reaction to mine. She too was wracked with guilt and grief. Mel had typed up her notes on the visit, and, whereas ordinarily, would have sent them to me as soon as they were completed, she felt it wasn't appropriate to do that on this occasion. She said this felt unfamiliar: like she was defying me, and worried that I would think her being slow to transcribe an interview was out of character, but nevertheless, let it sit on her computer for the time being. I was grateful to Mel for waiting until I was more robust to share this news and saw it as an instance of her practicing relational ethics which 'requires researchers to act from our hearts and mind, acknowledge our interpersonal bonds to others and take responsibility for actions and their consequences' (Ellis 2007, 1).

Approximately a year later there was another incident where the project and my life dramatically coincided. It was Dementia Awareness Week and our work received coverage in the media including in a film made for Channel 4 news in which two participants and myself talked about living with someone with YOD. I felt that the film was excellent and, being a bit of a waterworks, had started crying right at the start of the broadcast due to the poignancy of the stories, out of gratitude for sensitive and ethical coverage, and because I felt the programme met the project aim of raising awareness about the impact of parental YOD on young people. Over the next few hours there were more tears as emails and texts arrived from people - known and unknown - who'd seen the programme. Sleep came early.

Waking at 5 I looked at my phone and saw that there was a missed call that I'd slept through and a voicemail from the care home. Within 10 minutes I was on my way to 
the hospital where my husband had been taken in the early hours following yet another seizure and a fall. My switch flipped from being an academic researching and disseminating what it is like to live with YOD to being a family member living that life. Once again I had to take a couple of weeks leave to regroup and to enable my two dementia selves to achieve some equilibrium.

\section{Dealing with distress what we did and what others might do}

Within the literature dealing with sensitive research and potential harm to researcher emotional and psychological wellbeing, various strategies are recommended. These include: drawing on informal peer support; using the sort of supervisory arrangements and processes common in healthcare and social work settings; including funding for professional support in bids for projects dealing with sensitive topics; raising awareness by addressing the risks of emotional and psychological distress during doctoral training programmes; and the provision by universities of support services to deal with researcher distress (see, for example, Bloor, Fincham and Sampson 2007; Dickson-Swift et al 2007, 2008, 2009). The British Educational Research Association's ethical guidelines contains an, albeit brief, section on 'responsibilities for researchers' well being and development' (BERA 2018, 35 - 36) which does acknowledge that there are risks for educational researchers but it seems fair to say that we are not as far down the road as other disciplinary areas in anticipating or recognizing them.

For our part we debriefed as part of the project, and in line with our caring, relational approach, as we considered/analysed and shared emotions about data and participants. We also spoke about our experiences with colleagues, friends and family and the 
researchers, practitioners and people living with YOD we met through the various dementia organisations and networks we became involved with. Unsurprisingly perhaps, these last proved to be very helpful because they had informed notions of what we were talking about and could, therefore be especially supportive. It has been particularly valuable to be able to share with people with a diagnosis of dementia the 'negative' perceptions and experiences participants have expressed and to explore both how they feel about these and their thoughts concerning how we should represent and disseminate them. These people have always encouraged us to report what we were told. In our view taking this line both allies with our commitment and gives a warrant to the project aim of seeking to understand what it is like to be a child or young person with a parent with YOD in order to lay an evidence base to inform policy and practice leading to the provision of appropriate support. Having 'permission' from those living with YOD to report frankly also helps ease some of our uneasiness around challenging master narratives that we talked about earlier.

This commitment has, in fact, been central in providing us with the strength to keep on doing the emotional work necessary to hear, to empathise with, and to make sense of the distressing stories (emerald and Carpenter 2015). We agree with Denise Turner who cites bell hooks and suggests that it is important to confront the pain we feel as a potentially

'necessary process in creating new knowledge from traumatic experience....[and that] being courageous enough to represent our own pain and those of others within social science research changes the discourse into something capable of change and growth' $(2015,85)$ 
This position articulates with Pat's adoption of the Millsian imperative to make private troubles public concerns.

Something else that we did that helped us deal with our distress was to support participants where we could, either by providing information, signposting to resources and support or, in a few cases, where people had said they had never met anyone else experiencing parental YOD and would like to, linking them up with another participant. On a number of occasions when, through a transcript or from something Mel said, Pat learned that a participant or a member of their family was going through a difficult experience that she had also had, she made contact and offered experientially based understanding and sympathy. She did this, for instance, with the woman who had placed her husband in care and both of them benefitted from sharing the deeply traumatic experience and the overwhelming sense of guilt that accompanied it. Such action is in the tradition of Ann Oakley's call for 'no intimacy without reciprocity' $(1981,49)$ which came to be a central tenet of

'feminist research principles, no pain no gain... This is not just the price of qualitative research it is the price of human understandings in our everyday lives and it is one which the evidence suggests is broadly viewed by researchers as a price worth paying’ (Sampson, Bloor and Fincham, 2008, 930).

This was certainly our view and we share Ivor Goodson's credo that, as far as proves possible, 'purposes have to be pursued passionately, otherwise there is no point in pursuing what you believe in. Our purpose is a simple one, to try and work for a reasonable just, human, civilized society where everybody is treated equally.' 
(quoted in Aadlandsvik, undated). We became increasingly committed to and consumed by the project and we wouldn't have had it any other way. Having said that there definitely have been times when Pat has felt overwhelmed with sadness about the participants' and her own family's experiences with dementia and has had to temporarily distance herself from the study in order to be able to return to it. Recognising Mel's similar need to detach on occasion Pat offered the option of working at home or working shorter hours on interview days or upon completing a difficult transcript. This may not be something all Principal Investigators are prepared or able to do, but is important to at least consider providing such leeway on demanding projects. Such distancing can be seen in terms of withdrawing on-going consent for a period of time or entirely - an option that is reiterated to participants but which researchers may have not traditionally considered as a possibility for their own involvement. Having said this it is important to note that we acknowledge that there can come a time when enough is enough and the research should be stopped, as Blee (2003) decided to do after studying female members of the Klu Klux Klan for two decades. There is no shame in looking after our own wellbeing as we would that of participants when the personal costs do become too harmful - although we are aware of how this can conflict with the expectations and requirements of universities and funders.

As educational researchers working - or proposing to work - in sensitive and sometimes distressing areas we do need to be aware of the risks and consider what we can do to protect ourselves, whether through practical or cognitive strategies. We also need to be aware that auto/biographical investigations that may not initially look likely to be emotionally and psychologically disturbing - that come too close to 
comfort because they touch on our own and participants' lives - can become so and be ready to recognise when this happens. This point is especially pertinent because we did start knowing that the work would painful. What we didn't know was how events in our lives would intervene. As Blee notes, 'we are most honest as scholars when we acknowledge the myriad ways in which our personal lives and emotions are intertwined with who, what, and how we study' (2003, 22). And we need to acknowledge too that we cannot always anticipate how this will happen.

Finally we should point out that our chief safeguards were our embracing of a caring relational approach to ethics that we applied to our dealings with research participants and each other, and the trusting and collaborative research relationship and friendship we developed throughout the course of the study and beyond. This relationship not only provided emotional support but also enabled us to build on the insights and knowledge from sharing ideas and feelings that contributed to strengthening our analysis. Whilst obviously not all researchers are able to work with someone else we would suggest that it is a significant benefit when working in sensitive areas that can come too close to comfort. We were lucky. Others may have to work harder to ensure that appropriate safeguards are built in but it is important to do so both in terms of protecting researchers and with respect to ensuring that projects aimed at making a positive difference have the best chances of achieving their aims.

\section{Notes}

1. All names are pseudonyms. 


\section{Funding}

This project was supported by Alzheimer's Society grant R138585

No financial interest or benefit that has arisen from the direct applications of this research.

\section{References}

Aadlandsvik, R. (Undated) Conversations with Ivor Goodson over the last two decades. Taped and transcribed. Unpublished.

Allen, J., Oybode, J. and Allen, J. 2009. "Having a father with young onset dementia: the impact on the well being of young people." Dementia 8 (4): $455-480$.

Aslett, H., Huws, J., Woods, R. and Kelly-Rhind, J. 2017. "“This is killing me inside': the impact of having a parent with young-onset dementia”. Dementia. Advance online publication. doi.org/10.1177/1471301217702977

Behar, R. 1996. The vulnerable observer: anthropology that breaks your heart. Boston: Beacon Press.

British Educational Research Association [BERA]

Ethical Guidelines for Educational Research, fourth edition, London. https://www.bera.ac.uk/researchers-resources/publications/ethical- guidelinesfor-educational-research-2018

Blee, K. 2003. 'Studying the enemy'. In B. Glassner and R. Hertz (Eds) 13 - 23 Our studies, ourselves: sociologists' lives and work. New York, Oxford University Press. 
Bloor, M., Fincham, B. and Sampson, H. 2007. Qualiti (NCRM) commissioned inquiry into the risk to well-being of researchers in qualitative research. Cardiff, UK: School of Social Sciences. Retreived from http://eprints.ncrm.ac.uk/407/1/CIReport.pdf 15/10/18.

Brooks, R., te Riele, K. and Maguire, M. 2014. Ethics and education research. London, Sage.

Chatham-Carpenter, A. 2018. “'Do thyself no harm': protecting ourselves as autoethnographers." Journal of Research Practice 6(1), Article M1. Retrieved [8/10/18], from http://jrp.icaap.org/index.php/jrp/article/view/213/183.

Dickson-Swift, V. James, E., Kippen, S. and Liamputtong, P. 2007. “Doing sensitive research: what challenges do qualitative researchers face?". Qualitative Research 7 (3): 327 -353.

Dickson-Swift, V. James, E., Kippen, S. and Liamputtong, P. 2008. "Risk to researchers in qualitative research on sensitive topics: issues and strategies." Qualitative Health Research 18 (1): 133 - 144.

Dickson-Swift, V. James, E., Kippen, S. and Liamputtong, P. 2009. "Researching sensitive topics: qualitative work as emotion work." Qualitative Research 9 (1): $61-79$.

Ellis, C. 2007. 'Telling secrets, revealing lives: relational ethics in research with intimate others. Qualitative Inquiry. 13 (1): 3 - 29.

Ellis, C. 2017. 'Compassionate research: interviewing and storytelling from a relational ethics of care' in The Routledge international handbook on narrative and life history edited by I. Goodson et al 431 - 445. London, Routledge. 
Ellis, C. 2018. Final negotiations: a story of love, loss and chronic illness: revised and expanded edition. Philadelphia: Temple University Press.

Ellis, C. and Bochner, A. 2005. “Autoethnography, Personal Narrative, Reflexivity: researcher as subject." In Handbook of Qualitative Research: Second edition, edited by Norman Denzin and Yvonna Lincoln, 733 - 768. Thousand Oaks: Sage.

emerald, e. and Carpenter, L. 2015. "Vulnerability and emotions in research: risks, dilemmas and doubts." Qualitative Inquiry 21 (8): 741 - 750.

Gelman, C. and Rhames, K. 2016 "In their own words: the experiences and needs of children in younger-onset Alzheimer's disease and other dementias families." Dementia Advance online publication doi: 1471301216647097.

Goodson, I. and Sikes, P. 2001. Life history research in educational settings. Maidenhead, Open University.

Gullion, J. 2018. Diffractive ethnography: social science and the ontological turn. New York, Routledge

Goodson, I., Antikainen, A., Sikes, P. and Andrews, M. 2017. The Routledge International Handbook on Narrative and Life History. London: Routledge.

Hall, M. and Sikes, P. 2016a. "How do young people 'do' family when there is a diagnosis of dementia?" Families, Relationships and Societies. Advance online publication org/10.1332/204674316X14818999694306

Hall, M. and Sikes, P. 2016b. "'I'm not a carer': the identities of children and young people who have a parent with dementia" unpublished paper.

Hall, M. and Sikes, P. 2016c. 'From 'What the hell is going on?' to the 'Mushy middle ground' to 'Getting used to a new normal': young people's narratives around navigating parental dementia." Illness, Crisis and Loss. Advance 
online publication DOI:10.1177/1054137316651384 (gold access).

http://icl.sagepub.com/content/early/2016/05/26/1054137316651384.full.pdf+ html

Hall, M. and Sikes, P. 2017. “'It'd be easier if she'd died': young people with parents with dementia articulating inadmissible stories." Qualitative Health Research. Advance online publication doi/full/10.1177/1049732317697079

Harris, M. 2015. “"Three in the room': embodiment, disclosure and vulnerability in qualitative research.” Qualitative Health Research 25 (12): 1689 - 1699.

Hutchinson, K., Roberts, C., Kurrle, S. and Daly, M. 2014. “The emotional well being of young people having a parent with younger onset dementia." Dementia. Advance online publication 10.1177/1471301214532111.

Iphofen R. and Tolich, M. 2018. The Sage Handbook of Qualitative Research Ethics. London: Sage.

Jackson, A. and Mazzei, L. 2009. Voice in qualitative inquiry: challenging conventional, interpretative and critical conceptions in qualitative research. New York, Routledge.

James, A. 2005. "Life times: children's perspectives on age, agency and memory across the life course." In Studies in Modern Childhood: Society, Agency and Culture, edited by Jens Qvortrup, 248 - 266. London: Palgrave.

Kiyimba, N and O'Reilly, M. 2016. "The risk of secondary traumatic stress in the qualitative transcription process: a research note." Qualitative Inquiry 16 (4): $468-476$

Lather, P. 2009. 'Against empathy, voice and authenticity'. In A. Jackson and L. Mazzei (Eds) Voice in qualitative inquiry: challenging conventional, 
interpretative and critical conceptions in qualitative research $17-26$. New York, Routledge.

Lee, R. 1993. Doing research on sensitive topics. London: Sage.

Liddiard, K. 2013. Reflections on the process of researching disabled people's sexual lives." Sociological Research Online, 18, (3) 10 http://www.socresonline.org.uk/18/3/10html 10.5153/sro.3116 retrieved $8 / 10 / 18$

Mills, C.W. 1970. The Sociological Imagination. Penguin: Harmondsworth (first published in 1959 by Oxford University Press).

Nodding, N. 1984. Caring, a feminine approach to ethics and moral education. Berkeley, University of California Press.

Oakley, A. 1981. "Interviewing women: a contradiction in terms.” In Doing Feminist Research edited by Helen Roberts Doing Feminist Research 30 - 61. London: Routledge and Kegan Paul.

Pennebaker, J. 1990. Opening up: the healing power of expressing emotions. New York: Guilford Press.

Pietikainen, P. 2004. "Truth hurts: the sociobiology debate, moral reading and the idea of 'dangerous knowledge'.” Social epistemology 18 (2-3): 165 - 179.

Renzetti, C. and Lee, R. (Eds). 1993. Researching sensitive topics. Newbury Park: CA, Sage.

Sampson, H., Bloor, M. and Fincham, B. 2008. “'A price worth paying?': considering the 'cost' of reflexive research methods and the influence of feminist ways of ‘doing.' Sociology 42 (5): 919 - 933.

Sikes, P. 1997. Parents Who Teach: Stories From Home and From School. London: Cassells. 
Sikes, P. 2006. "On Dodgy Ground? Problematics and Ethics in Educational Research?." International Journal of Research and Method in Education 29 (1): $105-117$

Sikes, P. 2015. "Hijacked by the project?: Research which demands to be done." Research in Teacher Education 5 (1): 45 - 50.

Sikes, P. and Hall, M. 2016. "'It was then that I thought 'whaat? This is not my Dad': the implications of the 'still the same person' narrative for children and young people who have a parent with dementia" Dementia. Advance online publication DOI:10.1177/1471301216637204.

Sikes, P. and Hall, M. 2017. “"Every time I see him he's the worst he's ever been and the best he'll ever be': and sadness in children and young people who have a parent with dementia." Mortality 22, (4): $324-388$.

Sikes, P. and Hall, M. 2018. "The impact of parental young onset dementia on children and young people's educational careers.” British Educational Research Journal 44 (4): 593 - 607.

Sikes, P. and Piper, H. 2010. Researching Sex and Lies in the Classroom: Allegations of Sexual Misconduct in Schools. London: Routledge/Falmer.

Sikes, P. and Potts, A. (Eds) 2008. Researching education from the inside: investigations from within. London, Routledge.

Stanley, L. 1993. "The knowing because experiencing subject: narratives, lives, autobiography." Women's studies international forum 16 (3): 205 - 215.

Tillmann-Healy, L. 2003. 'Friendship as method'. Qualitative Inquiry 9 (5): 729 749.

Tillmann-Healy, L. and Kiesinger, C. (2001) 'Mirrors: seeing each other and 
ourselves through fieldwork'. In The emotional nature of qualitative research edited by K. Gilbert. Boca Raton, CRC Press.

Turner, D. 2016. “'Research you cannot talk about': a personal account of researching sudden, unexpected child death.” Illness, crisis and loss 24 (2): 73 - 87.

Turner, L., Short, N., Grant, A. and Adams, T. 2018. International perspectives on autoethnographic research and practice. New York: Routledge.

Van Maanen, J. 1988. Tales of the field: on writing ethnography. Chicago: University of Chicago Press.

Young Dementia UK. 2015. Young Onset Dementia: Facts and Figures. http://www.youngdementiauk.org/young-onset-dementia-facts-figures Accessed : 8/10/18. 